\title{
Residue concentration of cefquinome after intramammary dry cow therapy and short dry periods
}

\author{
J. Bachmann, ${ }^{*}$ C. Helmschrodt, $†$ A. Richter, $†$ W. Heuwieser, ${ }^{* 1}$ and S. Bertulat* \\ ${ }^{*}$ Clinic for Animal Reproduction, Faculty of Veterinary Medicine, Freie Universität Berlin Königsweg 65, 14163 Berlin, Germany \\ †Institute of Pharmacology, Pharmacy and Toxicology, Faculty of Veterinary Medicine, University of Leipzig, An den Tierkliniken 15, 04103 Leipzig, \\ Germany
}

\section{ABSTRACT}

Short dry periods and their effects on milk production, reproductive performance, as well as cow and udder health have been widely studied. A dearth of information is available about the consequences of short dry periods on the residue concentrations of dry cow antibiotics in milk after calving. The objective of our study was to determine the residue concentration of a dry cow antibiotic in milk after short dry periods during the colostrum period and early lactation. Quarters of 19 dry cows were treated with an intramammary (IMM) dry cow antibiotic containing $150 \mathrm{mg}$ of cefquinome on d 21, 14, and 7 before calculated calving date. One quarter of each cow did not receive treatment and served as negative control. After calving, quarter foremilk samples were collected twice daily until $21 \mathrm{~d}$ and once daily until $36 \mathrm{~d}$ after IMM dry cow treatment (i.e., end of withdrawal period). A total of 588 foremilk samples from odd milking numbers were chosen for the determination of the residue concentration of cefquinome using HPLC-tandem mass spectrometry until the residue concentration fell below the limit of quantification (1 ng/g), which occurred at the latest in milking number 37 . The dry period length of the treated quarters was categorized in 3 dry period groups ranging from 1 to $7 \mathrm{~d}(4.8 \pm 2.4), 8$ to $14 \mathrm{~d}(11.5$ $\pm 2.3)$, and 15 to $26 \mathrm{~d}(19.5 \pm 3.3 ; \pm \mathrm{SEM})$, in dry period group 1, 2, and 3, respectively. In dry period group 1, the cefquinome concentration increased after calving until the third milking and decreased considerably until the fifth milking. In dry period group 2, the cefquinome concentration peaked at the second milking and decreased considerably until the fifth milking as well. There was no increase in cefquinome after calving in dry period group 3. Up to the 37th milking, the cefquinome concentration was higher in dry period

Received September 12, 2017.

Accepted April 9, 2018.

${ }^{1}$ Corresponding author: w.heuwieser@fu-berlin.de group 1 than in dry period group 2 and 3. On average, $31.3 \pm 1.2,19.0 \pm 1.1$, and $6.7 \pm 0.8$ milkings and 19.4 $\pm 0.4,20.6 \pm 0.5$, and $24.1 \pm 0.7 \mathrm{~d}$ after treatment were necessary for the concentration of cefquinome to fall below the maximum residue limit (MRL) in dry period group 1, 2, and 3, respectively. These results indicate that shorter dry periods lead initially to higher cefquinome residues in milk. The residue concentration after experimental short dry periods still falls below the MRL within the recommended withdrawal period for milk of $36 \mathrm{~d}$ after IMM dry cow treatment. For the sake of food safety and economics, these short dry periods should not be used in the dry cow management, as they lead up to a maximum of $31.3 \pm 1.2$ milkings and 19.4 $\pm 0.4 \mathrm{~d}$ after treatment with cefquinome residues above the MRL. Therefore, a considerable number of milkings have to be discarded due to long withdrawal periods after calving.

Key words: dry period, antibiotic residue, cefquinome, withdrawal period

\section{INTRODUCTION}

An effective dry cow management including treatment with an antibiotic or internal teat sealant is an essential part of the international mastitis control program recommended by the National Mastitis Council (NMC, 2006). According to the US National Animal Health Monitoring System, about 93.0\% of US dairy cows received an intramammary dry ow antibiotic and averaged a dry period of $57.1 \mathrm{~d}$ (Lombard et al., 2015). A survey on commercial dairy farms in northern Germany revealed a blanket dry cow therapy on $79.6 \%$ of the farms and an average dry period of 7 wk (Bertulat et al., 2015). Short dry periods of $35 \mathrm{~d}$ or less were used in only $3.7 \%$ of the participating dairy farms (Bertulat et al., 2015). Short dry periods are considered a management strategy that could facilitate dry off and the transition period for high-producing cows (Lefebvre and Santschi, 2012).

Recently, several studies investigated the effects of short dry periods on production (Kuhn et al., 2006), 
reproductive performance (Shoshani et al., 2014), energy balance during early lactation (van Knegsel et al., 2014), and udder health (Church et al., 2008). A dry off 31 to $40 \mathrm{~d}$ before calving has been associated with maximized lifetime production after second or later lactation (Kuhn et al., 2006) and improved reproductive performance without any loss in colostrum quality (Shoshani et al., 2014). Furthermore, a dry period length of $30 \mathrm{~d}$ resulted in an improved energy balance of dairy cows in early lactation (van Knegsel et al., 2014) without any untoward effects on udder health (Church et al., 2008).

Santschi and Lefebvre (2014), however, hypothesized that short dry periods can be a risk factor for antibiotic residues in early lactation when cows calve early. To avoid antibiotic residues, withdrawal periods for milk are determined utilizing the time to safe concentration method, which calculates the number of milkings necessary for the residue concentration in milk to fall below the maximum residue limit (CVMP, 2000). For dry cow antibiotics, withdrawal periods for milk depend on the dry period length; thus, the residue depletion during the dry period and postcalving is considered (CVMP, 2006).

The potential effect of shortening the residue depletion during the dry period on the residue concentration of dry cow antibiotics after calving has not yet been investigated. Church et al. (2008) measured antibiotic residues in foremilk samples both from cows with regular dry period length (45 or $60 \mathrm{~d}$ ) that had been treated with a dry cow antibiotic and from cows with short dry periods $(30 \mathrm{~d})$ that had received a lactating cow antibiotic at dry off. Those authors did not find greater risk for antibiotic residues after short dry periods when cows were treated with a lactating cow antibiotic. When dry cow antibiotics are used, however, the risk for antibiotic residues after short dry periods might be greater, as antibiotics are pharmacologically designed to reach high and prolonged concentrations throughout the udder (Ehinger et al., 2006). Therefore, the objective of our study was to investigate the residue concentration of a dry cow antibiotic containing $150 \mathrm{mg}$ of cefquinome during the colostrum period and early lactation in quarter foremilk samples after short dry periods.

\section{MATERIALS AND METHODS}

\section{Animals and Eligibility Criteria}

The study was conducted between November 2014 and May 2015 at the Clinic for Animal Reproduction (Freie Universität Berlin, Berlin, Germany). To reduce the number of study animals, and in agreement with previous studies that suggested that udder quarters can be considered as independent entities (Schukken et al., 1993; Lindmark-Månsson et al., 2006), we choose a quarter-based approach. Previously dried-off cows (i.e., abrupt dry off with blanket dry cow treatment containing $150 \mathrm{mg}$ of cefquinome at least $57 \mathrm{~d}$ before calculated calving date) from a commercial dairy farm were selected and treated again with an intramammary (IMM) dry cow antibiotic in an extra-label manner within $21 \mathrm{~d}$ before calculated calving (i.e., $280 \mathrm{~d}$ after artificial insemination). This approach was favored because it minimized the effect and potential confounding of milk leakage on the residue concentration after calving, as milk leakage occurs most frequently within the first week after dry off (Bertulat et al., 2013). One quarter of each cow was not treated and served as a negative control (i.e., control quarters) to allow a quantification of potential residues from the first dry cow treatment and to determine if antibiotic concentrations could distribute among quarters.

Overall, 19 healthy, multiparous dry Holstein-Friesian and Holstein-Friesian crossbreed dairy cows were enrolled in the study $21 \mathrm{~d}$ before calculated calving date and followed until the end of the withdrawal period of the second dry cow treatment (i.e., maximum of $35 \mathrm{~d}$ after calving). We only enrolled dry cows with a calculated dry period length of at least $57 \mathrm{~d}$. This allowed a 36-d withdrawal period for the first dry cow treatment plus $21 \mathrm{~d}$ between second dry cow treatment and calculated calving. All cows were managed according to the guidelines set by the International Cooperation on Harmonization of Technical Requirements for Registration of Veterinary Medicinal Products (Hellmann and Radeloff, 2000). The experimental procedures reported herein were conducted with the approval of the Institutional Animal Care and Use Committee of Freie Universität Berlin. Enrolled cows were in good health (e.g., no mastitis, metabolic, or infectious disease) and had 4 functional quarters. Cows with clinical mastitis within the past $3 \mathrm{mo}$ or antibiotic treatment (i.e., IMM or systemic) other than dry cow therapy within the past 2 mo before enrolment were excluded from the study.

During their study period, cows were housed in groups of 4 or less in a freestall barn with 6 cubicles equipped with chopped straw-lime-water mixture and smooth concrete floor. For calving, cows were transferred to a calving pen after signs of imminent parturition (i.e., tail raising, vaginal discharge, abdominal contraction) had been identified. The calving pen (3.50 $\times 3.10 \mathrm{~m}$ ) was equipped with rubber mats and deepstraw bedding and was separated from the study cows by 2 metal fences. After calving, the cows and calves were separated immediately and cows were transferred back to the study group. 
All cows were fed grass silage, haylage, and hay ad libitum supplemented with standard dairy concentrate (MLF 18/3 Standard; BKF Belziger Kraftfutter GmbH, Bad Belzig, Germany) according to pregnancy status and milk yield. After calving, cows received a TMR formulated for fresh cows twice a day according to the NRC (2001) guidelines. Main ingredients were corn silage, rape, rapeseed extract, rye, hay, straw, and mineral supplements. Fresh water was available ad libitum.

\section{Precalving Study Protocol}

An initial examination of cows to be enrolled included a physical examination (i.e., respiration rate, body temperature, heart rate, rumen contraction), a trans-rectal manual pregnancy check, udder inspection (i.e., redness, swelling) and palpation (i.e., firmness, pain and heat), classification of teat end shapes (i.e., round, plate, inverted, pointed; Neijenhuis et al., 2000), and a check for hyperkeratosis (i.e., no ring, smooth or slightly rough ring, rough ring, very rough ring; Mein et al., 2001). The same investigator examined all cows.

To achieve antibiotic concentrations representative for short dry periods, 3 quarters of each cow received a single treatment with an IMM dry cow antibiotic (i.e., $150 \mathrm{mg}$ of cefquinome; Virbactan, Virbac Ltd., Carros, France) on a quarter individual basis on d 21, 14, and 7 before calculated calving date, respectively (i.e., treated quarters). This antibiotic treatment scheme falls into the category of extra-label drug usage, as all 4 quarters of a cow should be treated at the same time. It is a result of the quarter-based approach of our study with the above-mentioned advantages of reducing the number of study animals and minimizing the effect of milk leakage on the residue concentration after calving. The day of treatment was allocated to each quarter at random. A randomization list was generated with
Microsoft Excel (Microsoft Office 2010, Microsoft, Redmond, WA). All cows were treated by the same investigator and at the same time (i.e., $12.45 \mathrm{~h}$ ). Intramammary dry cow antibiotic was administered according to the summary of product characteristics provided by the manufacturer (http://www.vmd.defra.gov.uk/ productinformationdatabase/SPC_Documents/SPC _118464.DOC). In brief, teat ends were scrubbed with tissues soaked in $70 \%$ alcohol and the antibiotic suspension was infused into the quarter and massaged from the teat tip to the teat base to facilitate dispersion. The recommended withdrawal periods for the used dry cow antibiotic, when administered according to label instructions, are $1 \mathrm{~d}$ after calving and $36 \mathrm{~d}$ after treatment when the dry period is more and less than $35 \mathrm{~d}$, respectively (CVMP, 2006). The established MRL for cefquinome in milk is $20 \mathrm{ng} / \mathrm{g}$ (CVMP, 2003). After treatment, all quarters were monitored once a day at $0700 \mathrm{~h}$ for signs of clinical mastitis (i.e., firmness, pain, heat, redness, swelling) and twice a day for milk leakage (i.e., 0700 and 1300 h; Table 1). Milk leakage was recorded on the udder quarter level and defined as milk dripping or flowing from the teat.

\section{Postcalving Study Protocol}

After calving cows were milked twice daily, at 0700 and $1900 \mathrm{~h}$, using a portable bucket milking machine (i.e., GEA milking bucket with pulsator Vacupuls Constant; GEA Westfalia Separator AG, Oelde, Germany). The milking bucket was connected via vacuum line with a RPS Vacuum Pump ( $800 \mathrm{~L} / \mathrm{min})$ with a 3 -phase motor equipped with a typical milking cluster (Classic 300 milking cluster; GEA Westfalia Separator AG). Premilking procedures included wiping each teat wet and dry with an individual paper towel and discarding the first 3 streams of milk utilizing a premilking cup. Furthermore, foremilk from each quarter was checked

Table 1. Study protocol summarizing pre- and postcalving examinations

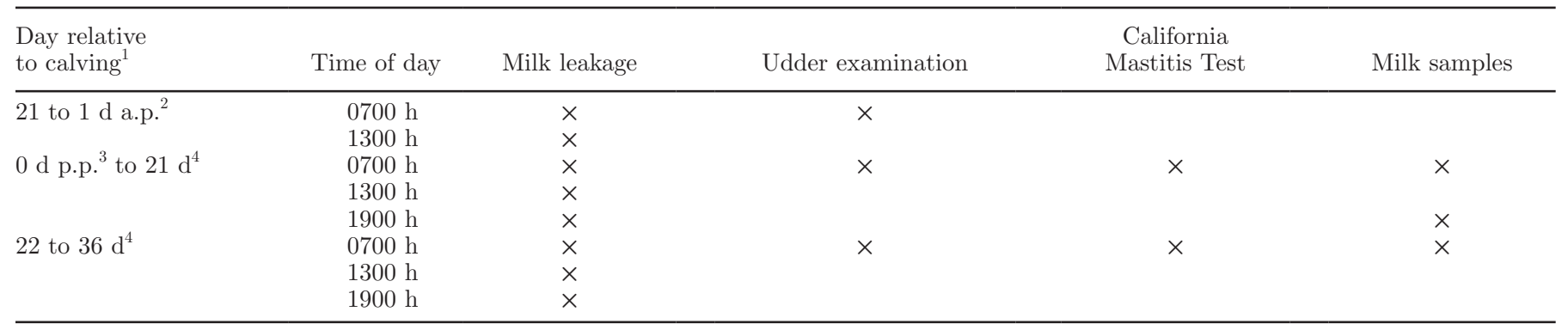

\footnotetext{
${ }^{1}$ Days before calculated calving date.

${ }^{2}$ a.p. = antepartum.

${ }^{3}$ p.p. $=$ postpartum.

${ }^{4}$ Days after last intramammary antibiotic treatment.
} 
daily at $0700 \mathrm{~h}$ for signs of clinical mastitis (i.e., clots, flakes) and subclinical mastitis using the California Mastitis Test (eimü Cell-Check 3S; Ferdinand Eimermacher GmbH \& Co. KG, Nordwalde, Germany). Udder quarters were monitored once a day at $0700 \mathrm{~h}$ for signs of clinical mastitis (i.e., firmness, pain, heat, redness, swelling) and thrice a day for milk leakage (i.e., 0700, 1300, and $1900 \mathrm{~h}$; Table 1). All cows with signs of clinical mastitis or systemic disease other than subclinical ketosis and all cows that received any antibiotic treatment beyond the IMM dry cow treatment were retrospectively withdrawn from the study.

\section{Sample Collection and Analysis}

Two foremilk samples (i.e., 13 and $30 \mathrm{~mL}$ ) from each quarter were collected before the morning milkings (i.e., $0700 \mathrm{~h}$ ) from d 1 until 36 after IMM antibiotic treatment (i.e., end of withdrawal period) and before the evening milkings (i.e., $1900 \mathrm{~h}$ ) from d 1 until 21 after IMM antibiotic treatment (Table 1). The foremilk samples were collected immediately after the premilking procedures.

The $30-\mathrm{mL}$ foremilk samples were stored at $6^{\circ} \mathrm{C}$ and transported within a maximum of $4 \mathrm{~d}$ to the local DHIA (Landeskontrollverband Berlin-Brandenburg eV., Waldsieversdorf, Germany) for milk composition analysis (i.e., fat, protein, lactose, urea, SCC). Fat, protein, and lactose were measured by mid-infrared spectroscopy according to IDF 141:2013 (IDF, 2013), and urea was determined by continuous flow analysis according to the guideline 1.13 of the German Association for Performance and Quality testing (DLQ, 2013). Somatic cell count was determined by flow cytometry according to IDF 148-2:2006 (IDF, 2006).

The $13-\mathrm{mL}$ foremilk samples were stored at $6^{\circ} \mathrm{C}$ for a maximum of $12 \mathrm{~h}$. Afterward samples were vortexed for $5 \mathrm{~s}\left(2400 \mathrm{~min}^{-1}\right)$, transferred to 5 -mL cryotubes (Cryovial, Simport, Bernard-Pilon, Canada), and frozen at $-80^{\circ} \mathrm{C}$ until analysis. The residue concentration of cefquinome was analyzed by HPLC-MS/MS with a limit of detection (LOD) of $0.2 \mathrm{ng} / \mathrm{g}$ and an interassay coefficient of variation between 8.5 (spiked quality control of $15 \mathrm{ng} / \mathrm{g}$ of milk) and $3.8 \%$ (spiked quality control of $45 \mathrm{ng} / \mathrm{g}$ of milk). For the quantification of cefquinome, $2 \mathrm{~g}$ of calibrators, controls, or bovine raw milk samples were mixed with $1 \mathrm{~mL}$ of internal standard solution in water. After protein precipitation and centrifugation $\left(10\right.$ min at $3,800 \times g$ at $\left.4^{\circ} \mathrm{C}\right)$, the supernatant fluid was transferred into a polypropylene tube and evaporated. Dried extracts were reconstituted to a volume of $1 \mathrm{~mL}$ and used for solid phase extraction. Extract fluid (10 $\mu \mathrm{L}$ ) was injected onto the analytic column (GeminiNX C18 110A $150 \times 3.0$ mm; Phenomenex, Aschaffen- burg, Germany). A 3200 QTRAP triple quadrupole mass spectrometer with an ESI ion source from Sciex (Darmstadt, Germany) was used as detector. Initially, the residue concentration of cefquinome was measured from all quarters from milking 1 (i.e., first milking after calving) and from treated quarters from milkings 2, 3, 5, and 7 (i.e., second, third, fifth, and seventh milking after calving). Further foremilk samples were individually selected for analysis based on measured residue values of previous milkings. Overall, foremilk samples from odd milking numbers up to maximum of the 37th milking were chosen for the analysis. When the residue concentration of a quarter fell below the limit of quantification (LOQ), we assumed that this concentration was maintained constantly until milking 37 . On d 36 after IMM antibiotic treatment, additional foremilk samples from all quarters were taken from all cows for a bacteriological examination.

\section{Statistical Analysis}

Data were entered into Excel spreadsheets (version 2010; Microsoft Corp.) and statistical analyses were performed with IBM SPSS Statistics (version 22.0; IBM Deutschland GmbH, Ehningen, Germany). Treated quarters were allocated to 1 of 3 groups based on the dry period length relative to the second dry cow treatment (i.e., dry period group 1: 1 to $7 \mathrm{~d}$; dry period group 2: 8 to $14 \mathrm{~d}$; dry period group $3:>14 \mathrm{~d}$ ). Effects of various parameters on the cefquinome concentration of the control quarter in the first milking (i.e., cefquinome concentration of the last treated quarter, the parallel quarter and all treated quarters; length of the dry period of the parallel quarter, the last treated quarter, length of the dry period after the first antibiotic dry cow treatment) and the treated quarters in the first milking and up to the 37th milking [i.e., lactation number, dry period length, dry period group, type of quarter (front or rear quarter), milk composition (fat, protein, lactose, SCC and urea), milk yield during a milking] were evaluated using mixed model ANOVA. Mixed models were built according to the model building strategies developed by Dohoo et al. (2009). The number of milkings was considered as repeated factor and quarter within cow was included as random effect. The number of milkings and the days after treatment until the concentration of cefquinome fell below the value for the maximum residue limit (MRL; i.e., 20 $\mathrm{ng} / \mathrm{g}$ ) in the different dry period groups were analyzed with a Kaplan-Meier analysis. Kaplan-Meier survival curves were produced using IBM SPSS Statistics. All values reported are least squares means \pm standard error of the means. The significance level was set at $P \leq$ 0.05 and tendencies were discussed at $P \leq 0.1$. 


\section{RESULTS}

Fourteen cows were used for the final analysis. Five out of 19 cows had to be retrospectively withdrawn from the study due to mastitis $(\mathrm{n}=1)$, ketosis $(\mathrm{n}=1)$, antibiotic treatment $(\mathrm{n}=1)$, and premature calving ( $\mathrm{n}$ $=1$ ). One cow died during the study period by rupture of the uterine artery. The 14 cows were $62 \pm 21$ mo old, in the second to sixth lactation, and their 305-d milk yield of the previous lactation averaged 10,079 \pm $1,267 \mathrm{~kg}$. Two cows calved before the dry cow treatment on $\mathrm{d} 7$ before the calculated calving date, and as a result these cows had 2 treated and 2 control quarters. A total of 56 quarters were used in the final analysis. The distribution of quarters was homogeneous between control quarters $(\mathrm{n}=16)$ and treated quarters of dry period group $1(\mathrm{n}=11), 2(\mathrm{n}=14)$, and $3(\mathrm{n}=15 ; P$ $=0.195$ ). The average dry period length of the control quarters was $78.1 \pm 23.4 \mathrm{~d}$, with $4.8 \pm 2.4$ (range $=1-7$ d), $11.5 \pm 2.3($ range $=8-14 \mathrm{~d}$ ), and $19.5 \pm 3.3 \mathrm{~d}$ (range $=15-26 \mathrm{~d}$ ) for groups 1,2 , and 3 , respectively. Only 1 cow showed milk leakage before calving; therefore, milk leakage was not considered in our analysis. A total of 2,392 foremilk samples were collected during the study period and 588 samples (i.e., 16 foremilk samples from control quarters and 206, 210, and 156 from dry period group 1, 2, and 3, respectively) were analyzed for the concentration of cefquinome using HPLC-MS/MS. The bacteriological examination at the end of the study period was negative for all cows.

\section{Control Quarters}

The average cefquinome concentration of the control quarters in the first milking was $2.91 \pm 1.47 \mathrm{ng} / \mathrm{g}$ (range: $0.5-5.57 \mathrm{ng} / \mathrm{g}$ ). It was not affected by the cefquinome concentration of the parallel quarter $(P=$ $0.794)$, all treated quarters $(P=0.715)$, the length of the dry period of the parallel quarter $(P=0.229)$, of the last treated quarter $(P=0.322)$, or the length of the dry period after the first antibiotic dry cow treatment $(P=0.267)$. There tended to be an effect of the concentration of the last treated quarter $(P=0.097)$, with higher concentrations in the control quarters when the concentration of the last treated quarter was also higher.

\section{Treated Quarters}

We found an exponential relationship between the number of days between treatment and calving and the initial cefquinome concentration. The correlation coefficient between the logarithm of cefquinome and days between treatment and calving was $-0.849(P<0.001$;
Figure 1). The average cefquinome concentration in the first milking was higher in dry period group $1(1,830.71$ $\pm 355.47 \mathrm{ng} / \mathrm{g} ; P=0.002)$ and $2(1,155.50 \pm 251.94$ $\mathrm{ng} / \mathrm{g} ; P=0.027)$ compared with the dry period group $3(77.59 \pm 65.45 \mathrm{ng} / \mathrm{g})$. Differences of the cefquinome concentration between dry period group 1 and 2 could not be detected $(P=0.201)$ in the first milking alone, but differences between the 2 dry period groups could be detected up to the 37th milking, which are described below. The concentration of cefquinome was further related to lactose content, with higher concentrations when the lactose content was higher as well $(P=0.048)$. The cefquinome concentration of the treated quarters in the first milking was not affected by the number of lactation $(P=0.856)$, the type of quarter $(P=0.441)$, fat $(P=0.626)$, protein $(P=0.161)$, urea content $(P=$ $0.682)$, SCC $(P=0.841)$, or milk yield during the first milking $(P=0.567)$.

The excretion of cefquinome of the treated quarters up to the 37th milking was affected by the number of milking $(P<0.001)$ and the dry period group $(P<$ 0.001 ), as well as by an interaction between the number of milking and the dry period group $(P<0.001)$. The average cefquinome concentration was higher in dry period group $1(581.40 \pm 90.71 \mathrm{ng} / \mathrm{g})$ than in dry period group $2(115.41 \pm 15.38 \mathrm{ng} / \mathrm{g} ; P=0.001)$ and $3(21.28$ $\pm 6.00 \mathrm{ng} / \mathrm{g} ; P<0.001)$. Cefquinome values measured in dry period group 1 remained higher than in dry period group 2 and 3 until the fifth milking $(P<0.05)$. No statistical difference could be detected between the cefquinome concentration of dry period group 2 and 3 for any of the milkings $(P=0.471)$. Interestingly, in dry period group 1, the cefquinome concentration increased after calving until the third milking $(P=$ $0.027)$, decreased considerably until the fifth milking $(P=0.001)$, and slowly decreased afterward. In dry period group 2, cefquinome concentration peaked at the second milking $(P<0.05)$, retained the same level as in milking 1 in milking $3(P=0.441)$, decreased considerably until the fifth milking $(P<0.001)$, and slowly decreased afterward. In dry period group 3, cefquinome concentration did not differ between the first and second milking $(P=0.994)$ but decreased between milking 2 and $3(P=0.069)$; afterward it slowly decreased until the end of the measuring period (Figure 2).

The cefquinome concentration after calving was additionally affected by milk yield, with higher concentrations when the milk yield during a milking was lower $(P=0.006)$. The number of milkings and protein ( $\mathrm{r}$ $=0.833)$ and lactose content $(\mathrm{r}=0.746)$ were highly correlated; as a result, only the number of milkings was used in the analysis. The number of lactation $(P=$ $0.510)$, type of quarter $(P=0.135)$, fat $(P=0.901)$, and urea content $(P=0.709)$ as well as $\operatorname{SCC}(P=$ 
0.241) had no effect on the cefquinome concentration of the treated quarters.

\section{MRL}

The first survival curve shows the time from the first milking after calving to the first milking with a cefquinome concentration below the MRL dependent on the dry period group (Figure 3 ). On average, $31.3 \pm$ $1.2,19.0 \pm 1.1$, and $6.7 \pm 0.8$ milkings were necessary for the concentration of cefquinome to fall below the MRL in dry period group 1,2 , and 3 , respectively $(P$ $<0.001)$. The number of days needed after treatment until the cefquinome concentration fell below the MRL differed between groups as well. The second survival curve shows the time from the day of treatment to the first day after treatment with a cefquinome concentration under the MRL depending on the dry period group (Figure 4). In dry period group 3, $24.1 \pm 0.7 \mathrm{~d}$ were necessary, whereas in dry period group 2 and 1 only $20.6 \pm 0.5(P=0.003)$ and $19.4 \pm 0.4 \mathrm{~d}(P<0.001)$ were needed, respectively. A maximum of 22,23 , and $28 \mathrm{~d}$ after treatment in dry period group 1, 2, and 3, respectively, were needed for the cefquinome concentra- tion to fall under the MRL. These results indicate that, in all dry period groups, cefquinome concentration went below the MRL before the regular withdrawal period of $36 \mathrm{~d}$ after IMM dry cow treatment ended and they show a safety margin of at least $1 \mathrm{wk}$.

\section{DISCUSSION}

\section{Control Quarters}

In our study, 1 quarter of each cow was not treated a second time with an IMM dry cow antibiotic to serve as a negative control quarter. Minor cefquinome residues (range $=0.5-5.59 \mathrm{ng} / \mathrm{g}$ ), albeit far below the MRL (i.e., $20 \mathrm{ng} / \mathrm{g}$ ), could be detected in the foremilk samples of the control quarters of the first milking. Interestingly, we found no association between the concentration of the control quarters and the dry period length after the first dry cow treatment but a weak association with the last treated quarters. These results challenge the assumed independence of the udder quarters in our study design, as they indicate a certain diffusion of cefquinome between the quarters and not a persistence of residues from the first dry cow treatment. The assump-

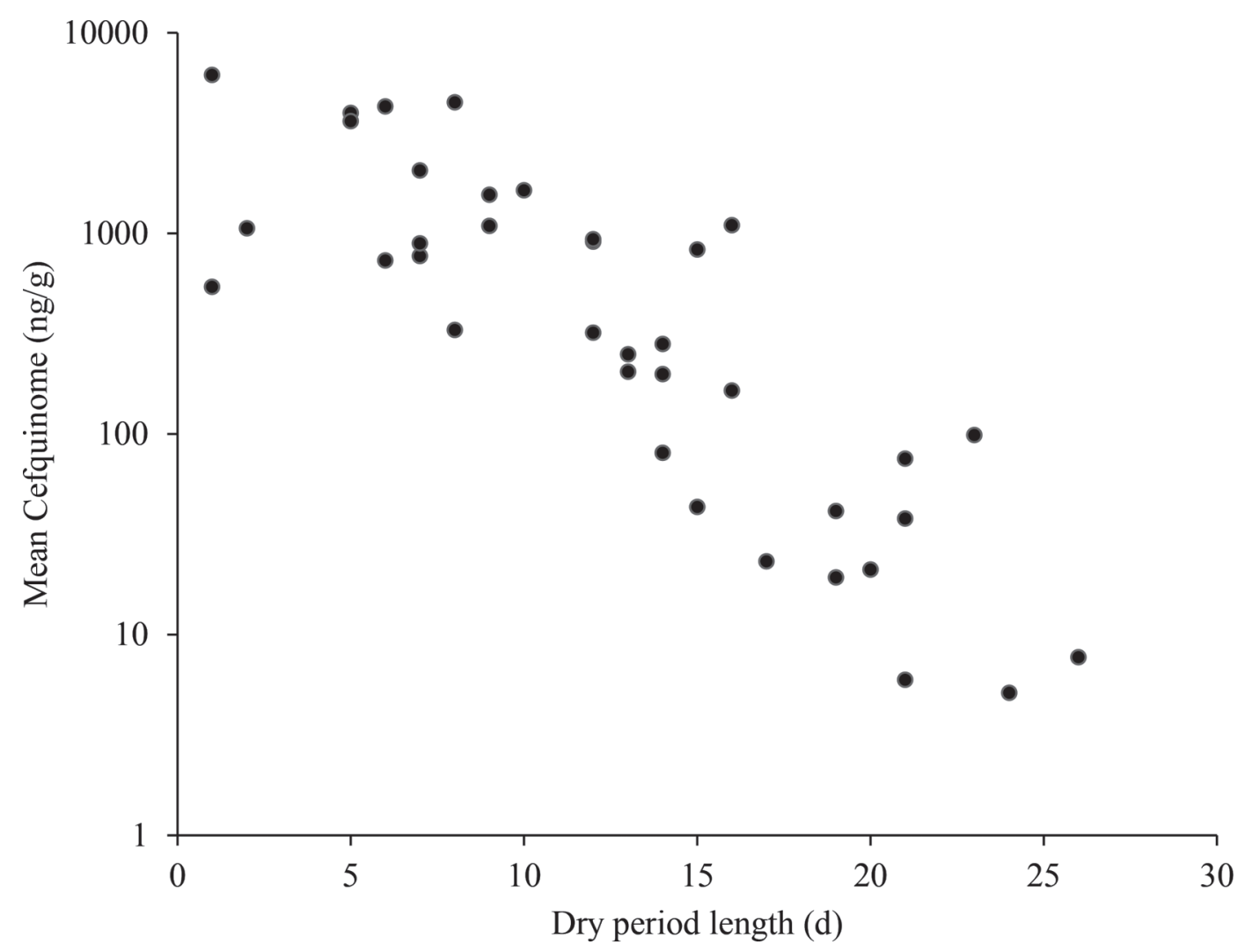

Figure 1. Relationship between initial cefquinome concentration in the first milking after calving and the dry period length. Mean concentration of cefquinome on logarithmic scale. 


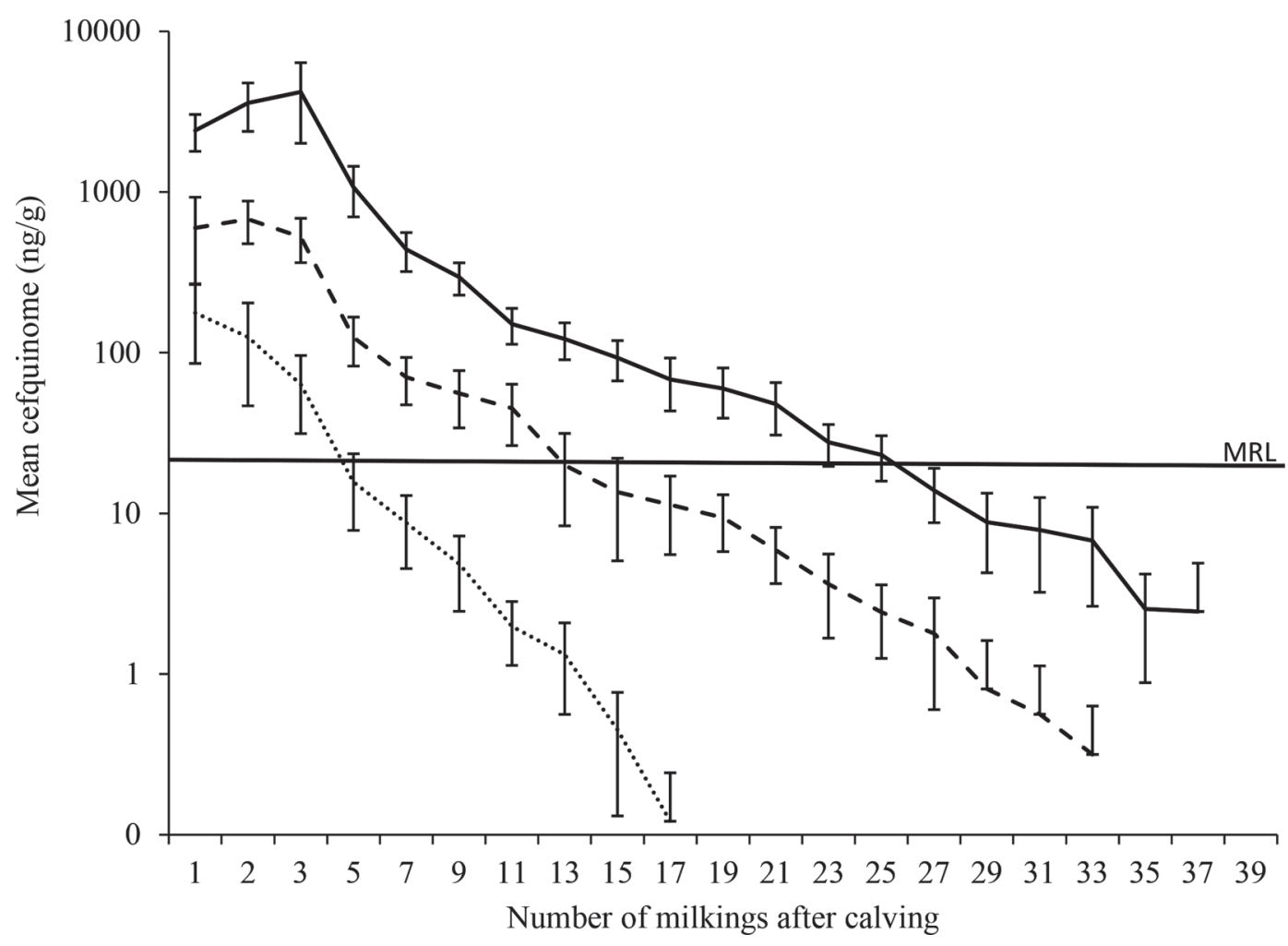

Figure 2. Mean concentration of cefquinome on logarithmic scale during the whole study period in dry period group 1 (1 to 7 d; solid line), group 2 ( 7 to $14 \mathrm{~d}$; dashed line), and group 3 ( $>14 \mathrm{~d}$; dotted line) plotted with maximum residue limit (MRL; $20 \mathrm{ng} / \mathrm{g}$ ). Error bars show SEM.

tion of independent udder quarters was based on previous observations. Schukken et al. (1993) performed a pilot study on 10 cows and treated 1 udder half (left or right) of each cow with a dry cow antibiotic containing procaine penicillin (300,000 IU), nafcillin (100 mg), and dihydrostreptomycin (100 mg). Those authors tested milk samples from the untreated quarters during the first $10 \mathrm{~d}$ of the dry period with the Delvotest SP assay (i.e., limit of detection for penicillin $=2 \mathrm{ng} / \mathrm{mL}$, nafcillin $=5 \mathrm{ng} / \mathrm{mL}$, and dihydrostreptomycin $=300-500$ ng/mL; DSM Food Specialties B.V., Delft, the Netherlands) and reported that none of the untreated quarters showed any evidence that concentrations of the dry cow antibiotic crossed from treated to untreated quarters. Likewise, the milk composition in udder quarter milk samples were considered independently by LindmarkMånsson et al. (2006).

In contrast to these studies, Barkema et al. (1997) detected a strong interdependence between high SCC and IMI of quarters within a cow and recommended statistical correction of the interdependence of quarters in studies on subclinical mastitis. A most recent work (Li et al., 2014) published after our study started, measured cefquinome concentrations in milk samples from treated and untreated parallel quarters after 1 and 3 consecutive IMM administrations of $75 \mathrm{mg}$ of cefquinome in lactating cows. Those authors detected cefquinome concentrations from 5 to $80 \mathrm{ng} / \mathrm{g}$ at $6 \mathrm{~h}$ after treatment in untreated quarters. This could be observed in 4 out of 6 cows, and those authors explained the occurrence with diffusion or distribution of cefquinome between the quarters (Li et al., 2014). These and our findings, however, are in contrast to the pharmacokinetic characteristics of cefquinome. In general, the ability of cefquinome to distribute through the udder and diffuse through lipophilic membranes is low, as it is a weak organic acid with a low fat solubility. Furthermore, it has an acid dissociation constant (i.e., pKa) of 2.51 and 2.91, which means that in milk with a $\mathrm{pH}$ of 6.4 to 7.0 a higher proportion of molecules is ionized (CVMP, 1995; Gehring and Smith, 2006). These pharmacokinetic characteristics of cefquinome would support our quarter-based approach; however, further research is necessary to elucidate the origin of the cefquinome residues in the control quarters and to investigate if the assumption of independent quarters is in fact valid. In previous studies, minor residue concentrations in control quarters might not have been detected due to a higher LOD of the used measurements methods. For comparison, the Committee for Veterinary Medici- 
nal Products validated a reversed-phase HPLC for the determination of cefquinome in milk with a LOD of $10 \mathrm{ng} / \mathrm{g}$ and a LOQ of $15 \mathrm{ng} / \mathrm{g}$ (CVMP, 1995). Li et al. (2014) used an HPLC-MS/MS with a LOD of 2 $\mathrm{ng} / \mathrm{g}$ and a LOQ of $5 \mathrm{ng} / \mathrm{g}$ for the determination of the cefquinome concentration, whereas the HPLC-MS/MS in our study had a LOD of $0.2 \mathrm{ng} / \mathrm{g}$ and a LOQ of 1 $\mathrm{ng} / \mathrm{g}$. These high sensitivities might have allowed the detection of minor cefquinome residues in the control quarters that might not have been detected before.

Overall, the residues detected in our control quarters averaged $0.28 \%$ of the antibiotic concentration measured in all quarters. Considering the proportion of cefquinome in the treated and control quarter, the measured cefquinome concentrations of the treated quarters might be slightly underestimated. Even if the detected numerical association between the cefquinome concentration of the last treated quarter and the control quarter would be based on a certain diffusion between the quarters, the effect of this diffusion on the concentrations of the treated quarters would be negligible.

\section{Treated Quarters}

We measured cefquinome concentrations in foremilk samples after a single, extra-label IMM treatment with a dry cow antibiotic followed by experimental short dry periods from $1 \mathrm{~d}$ to a maximum of $26 \mathrm{~d}$. These dry period lengths could occur when cows with short dry periods of 20 to $40 \mathrm{~d}$ calve early. With our study design, which includes a second dry cow treatment of previously dried-off cows, we could minimize the losses of antibiotic residues by milk leakage before calving, and thus confounding of results, as IMM administered cefquinome is mainly excreted with the milk (CVMP, 1995).

We were able to demonstrate that the dry period length affected the residue concentration of cefquinome in foremilk samples after calving. In the first milking, the cefquinome concentration was significantly higher in dry period groups 1 and 2 than in dry period group 3. A residue depletion study (CVMP, 2006) in milk from dairy cows after an IMM treatment with $150 \mathrm{mg}$

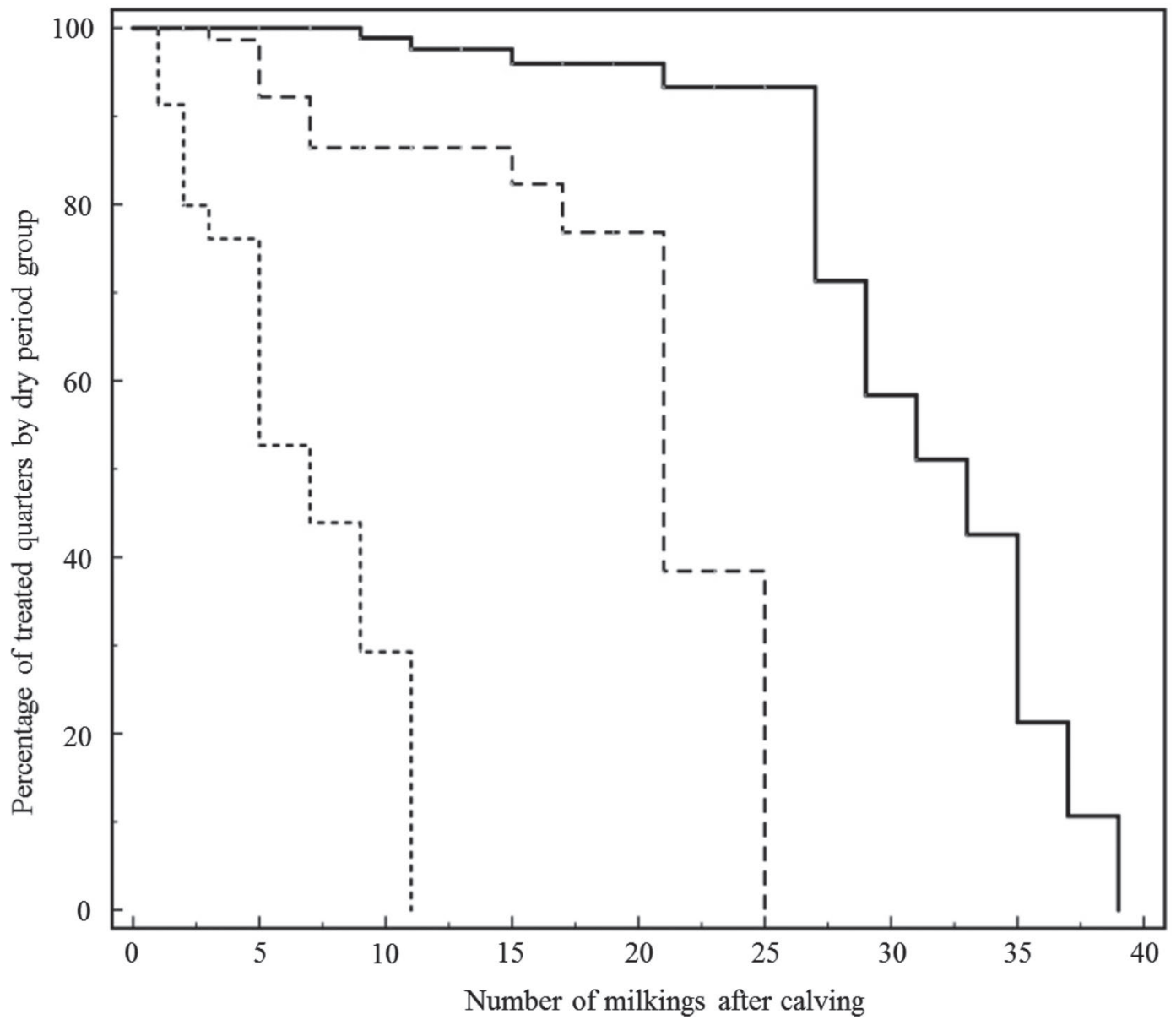

Figure 3. Kaplan-Meier curve from the first milking after calving to the first milking with a cefquinome concentration under the maximum residue limit (MRL) in dry period group 1 ( 1 to $7 \mathrm{~d}$; solid line), group 2 ( 7 to $14 \mathrm{~d}$; long dashed line), and group 3 ( $>14 \mathrm{~d}$; short dashed line). 
cefquinome, followed by short dry periods varying from 16 to $36 \mathrm{~d}$, found that the dry period had a significant effect on the residues at the first milking due to the wide range of dry periods and the substantial depletion of residues from the udder quarters during the dry period. The depletion of cefquinome during the dry period is followed by a more rapid depletion after calving (CVMP, 2006), which could be confirmed by our results. Up to the fifth milking, the cefquinome concentration in dry period group 1 was significantly higher than in dry period group 2 and 3 . The more rapid, exponential depletion after calving seemed to compensate for the effect of the dry period group on the cefquinome concentration in our study. The difference between dry period group 2 and 3 in the first milking was not detectable in the second ANOVA, and no difference could be detected between the 2 dry periods groups in any later milking. In cistern milk samples from healthy quarters, cefquinome concentrations could be detected until the ninth milking from lactating cows after 3 consecutive IMM treatments with $75 \mathrm{mg}$ of cefquinome (Zonca et al., 2011). Li et al. (2014) reported maximum levels of $598 \pm 323 \mu \mathrm{g} / \mathrm{mL}$ (i.e., 598,000 $\pm 323,000 \mathrm{ng} / \mathrm{g}$ ) of cefquinome in milk at $2 \mathrm{~h}$ after a single IMM administration of $75 \mathrm{mg}$ of cefquinome; those authors also reported a monoexponential decline to low levels of $0.01 \pm 0.005 \mu \mathrm{g} / \mathrm{mL}$ (i.e., $10 \pm 5 \mathrm{ng} / \mathrm{g}$ ) at $72 \mathrm{~h}$ after the administration. In contrast to these 2 studies investigating a lactating cow antibiotic with $75 \mathrm{mg}$ of cefquinome and showing a continuous decline of the residue concentration, our study showed that in dry period groups 1 and 2 the concentration of cefquinome increased until the third and second milking, respectively. Afterward, the cefquinome concentration decreased until the fifth milking. We hypothesized that some characteristics of the colostrum might hinder the release of cefquinome from the dry cow formulation, but might speed up after the first milking and thus lead to the higher concentrations in the second and third milking. This effect might be weaker when the dry cow antibiotic remains longer in the dry udder, which could explain the smaller increase of the cefquinome concentration in dry period group 2 and no increase in dry period group 3, respectively. The considerable decrease

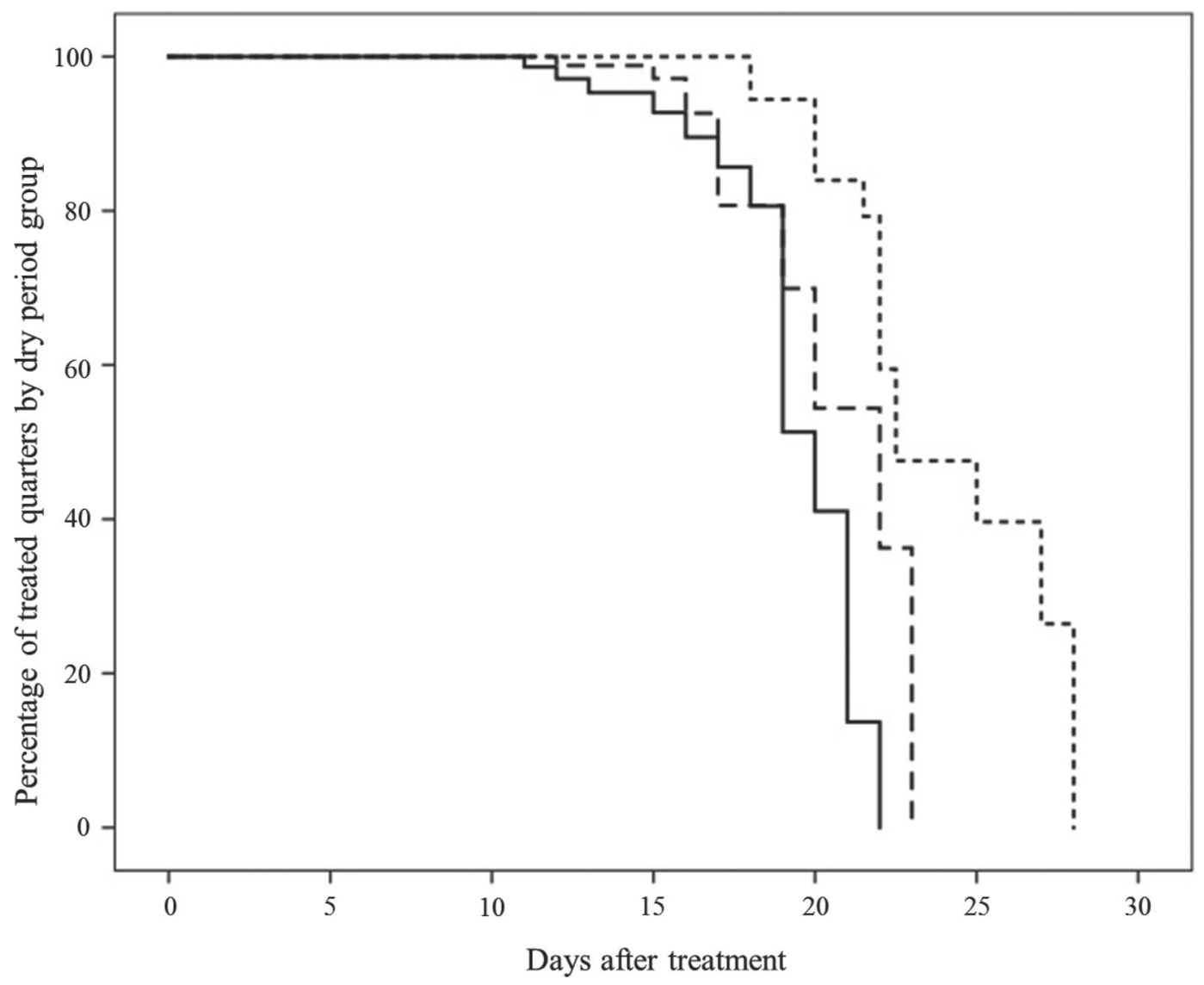

Figure 4. Kaplan-Meier curve from the day of treatment to the first day after treatment with a cefquinome concentration under the maximum residue limit (MRL) in dry period group 1 (1 to $7 \mathrm{~d}$; solid line), group 2 (7 to $14 \mathrm{~d}$; long dashed line), and group 3 (>14 d; short dashed line). 
of the cefquinome concentration between the third and fifth milking in dry period group 1 might be related to the transition from colostrum to milk accompanied by an increasing milk yield and the exponential depletion of the cefquinome concentration.

We did not detect an effect of the milk composition on the cefquinome concentration after calving, except for the lactose content in the first milking. The cefquinome concentration in the first milking was higher when the lactose content was also higher. The physiological background of this effect remains unclear and, to our knowledge, no other study reported a similar effect. Due to the high correlation between protein and lactose content and the number of milkings, protein and lactose were excluded from further analysis and a potential effect on the cefquinome concentration up to the 37th milking could not be investigated in our study. As mentioned above, cefquinome has a low fat solubility (CVMP, 1995); thus, an effect of the fat content of the milk samples on the cefquinome concentration could be presumed. This hypothesis, however, could not be confirmed in our study, as the fat content had no effect on the cefquinome concentration in the first and up to the 37th milking.

We found a negative relationship between the cefquinome concentration and the milk yield. This is in contrast to previous reports, where a correlation between milk production and drug elimination of cefquinome or cefoperazone after IMM treatment in lactating cows could not be detected (Cagnardi et al., 2010; Zonca et al., 2011). Similar to our results, a correlation between milk yield and drug clearance after IMM administration of the lincosamide pirlimycin (Whittem, 1999) and various antibiotics against mastitis were described (Mercer et al., 1970). Low-producing cows (i.e., <9 $\mathrm{kg} / \mathrm{d}$ ) have been reported to eliminate antibiotics more slowly from the milk; however, the milk yield only partially explained the variations in milk-out rates, as several high-producing cows (i.e., $>23 \mathrm{~kg} / \mathrm{d}$ ) also eliminated antibiotic residues slowly (Mercer et al., 1970). As these results are inconsistent, and might be drug dependent (Gehring and Smith, 2006) and confounded through less sensitive methodologies, further research is necessary in this field.

\section{MRL}

The mean number of milkings and days after treatment until the cefquinome concentration fell below the MRL differed significantly between the 3 dry period groups. The mean number of milkings was higher when the dry period length was shorter. Dry period groups 1 , 2 , and 3 had an average of 31, 19, and 7 milkings with a cefquinome concentrations above the MRL. That shows a potential risk for food safety in the field if the recommended withdrawal periods are disregarded. In general, milk from individual cows with short dry periods should not be sold for human consumption before the withdrawal period is finished; furthermore, milk should be tested with an antibiotic screening test before selling for human consumption to ensure food safety. The total number of days necessary after treatment until the cefquinome concentration reached the MRL averaged 19, 21, and $24 \mathrm{~d}$ in dry period groups 1,2 and 3 , respectively; therefore, it was lower in cows with shorter dry periods. This is further proof of the more rapid depletion of cefquinome after calving compared with the dry period. The cefquinome concentration in our study fell below the MRL in all quarters within the recommended withdrawal period for milk of $36 \mathrm{~d}$ after IMM dry cow treatment, but the extra-label use of the dry cow antibiotic in our study has to be considered. Short dry periods, as investigated in our study, should not be used in dry cow management, as they lead to a considerable number of milkings that have to be discarded due to long withdrawal periods after calving, which displays an immense economically disadvantage in the field.

Nevertheless, further research is necessary to investigate the relationship between short dry periods and residue concentrations in milk for other dry cow antibiotics, as different pharmacokinetics and formulations can affect the residue depletion during the dry period and after calving. Therefore, the effect of short dry periods on the residue concentration after calving and the days after treatment needed for the residue concentration to fall below the MRL has to be evaluated for each dry cow formulation separately.

\section{CONCLUSIONS}

The results of this study indicate that shorter dry periods lead initially to higher cefquinome residues in milk. The residue concentration after experimental short dry periods still falls below the MRL within the recommended withdrawal period for milk of $36 \mathrm{~d}$ after IMM dry cow treatment. For the sake of food safety and economics, these short dry periods should not be used in the dry cow management, as they lead to a maximum of $31.3 \pm 1.2$ milkings and $19.4 \pm 0.4 \mathrm{~d}$ after treatment with cefquinome residues above the MRL; likewise, a considerable number of milkings have to be discarded due to long withdrawal periods after calving. These results cannot be transferred to other IMM dry cow antibiotics; therefore, further research on the effect of short dry periods on residue concentrations is needed. Furthermore, the validity of the independence of quarters should be investigated to decide if a 
quarter-based approach is an appropriate study design for future pharmacokinetic and residue studies.

\section{ACKNOWLEDGMENTS}

We gratefully thank the staff of the Clinic of Animal Reproduction (Freie Universität Berlin, Berlin, Germany) for their support during the practical part of the study. Furthermore, we thank the staff of the DHIA (Landekontrollverband Berlin-Brandenburg e. V., Waldsieversdorf, Germany) for their superb cooperation. This study was funded in part by the Federal Office of Consumer Protection and Food Safety (BVL, Braunschweig, Germany). Joana Bachmann was funded in part by a scholarship from Tiergyn Berlin e. V. (Berlin, Germany).

\section{REFERENCES}

Barkema, H. W., Y. H. Schukken, T. J. G. M. Lam, D. T. Galligan, M. L. Beiboer, and A. Brand. 1997. Estimation of interdependence among quarters of the bovine udder with subclinical mastitis and implications for analysis. J. Dairy Sci. 80:1592-1599.

Bertulat, S., C. Fischer-Tenhagen, and W. Heuwieser. 2015. A survey of drying-off practices on commercial dairy farms in northern Germany and a comparison to science-based recommendations. Vet. Rec. Open 2:e00068.

Bertulat, S., C. Fischer-Tenhagen, V. Suthar, E. Möstl, N. Isaka, and W. Heuwieser. 2013. Measurement of fecal glucocorticoid metabolites and evaluation of udder characteristics to estimate stress after sudden dry-off in dairy cows with different milk yields. J. Dairy Sci. 96:3774-3787.

Cagnardi, P., R. Villa, M. Gallo, C. Locatelli, S. Carli, P. Moroni, and A. Zonca. 2010. Cefoperazone sodium preparation behavior after intramammary administration in healthy and infected cows. J. Dairy Sci. 93:4105-4110.

Church, G. T., L. K. Fox, C. T. Gaskins, D. D. Hancock, and J. M. Gay. 2008. The effect of a shortened dry period on intramammary infections during the subsequent lactation. J. Dairy Sci. 91:4219-4225.

CVMP. 1995. Cefquinome. Summary Report. EMEA/MRL/005/95. European Agency for the Evaluation of Medicinal Products, Committee for Veterinary Medicinal Products, London, UK.

CVMP. 2000. Committee for Veterinary Medicinal Products: Note for Guidance for the Determination of Withdrawal Periods for Milk. EMEA/CVMP/473/98-final. European Agency for the Evaluation of Medicinal Products, Committee for Veterinary Medicinal Products, London, UK.

CVMP. 2003. Committee for Veterinary Medicinal Products: Cefquinome. Summary Report. EMEA/MRL/883/03-FINAL. European Agency for the Evaluation of Medicinal Products, Committee for Veterinary Medicinal Products, London, UK.

CVMP. 2006. EMEA/CVMP/269630/2006-EN. Annex II Scientific Conclusions and Grounds for the Variation of the Terms of the Marketing Authorisation. European Agency for the Evaluation of Medicinal Products, Committee for Veterinary Medicinal Products, London, UK.

DLQ. 2013. DLQ-Richtlinie 1.13. DLQ-Referenzmethode zur Bestimmung des Harnstoffgehaltes in Milch - Kontinuierliche Durchflussanalyse. Deutscher Verband für Leistungs- und Qualitätsprüfungen e.V., Bonn, Germany.

Dohoo, I. R., S. W. Martin, and H. Stryhn. 2009. Veterinary Epidemiologic Research. 2nd ed. University of Prince Edward Island, Charlottetown, PEI, Canada.
Ehinger, A. M., H. Schmidt, and M. Kietzmann. 2006. Tissue distribution of cefquinome after intramammary and "systemic" administration in the isolated perfused bovine udder. Vet. J. 172:147-153.

Gehring, R., and G. W. Smith. 2006. An overview of factors affecting the disposition of intramammary preparations used to treat bovine mastitis. J. Vet. Pharmacol. Ther. 29:237-241.

Hellmann, K., and I. Radeloff. 2000. Guidance for Industry: Good Clinical Practice. International Cooperation on Harmonisation of Technical Requirements for Registration of Veterinary Medicinal Products (VICH). VICH, Brussels, Belgium.

IDF. 2006. IDF 148-2:2006. Milk - Enumeration of somatic cells Part 2: Guidance on the operation of fluoro-opto-electronic counters. International Dairy Federation, Brussels, Belgium.

IDF. 2013. IDF 141:2013. Milk and liquid milk products - Guidelines for the application of mid-infrared spectrometry. International Dairy Federation, Brussels, Belgium.

Kuhn, M. T., J. L. Hutchison, and H. D. Norman. 2006. Dry period length to maximize production across adjacent lactations and lifetime production. J. Dairy Sci. 89:1713-1722.

Lefebvre, D. M., and D. E. Santschi. 2012. New concepts in dry period management. WCDS Adv. Dairy Technol. 24:203-218.

Li, Y.-F., L. Wang, X.-Y. Gu, Z.-L. Zeng, L.-M. He, F. Yang, B. Yuan, J.-H. Shu, and H.-Z. Ding. 2014. Pharmacokinetics and residues of cefquinome in milk of lactating chinese dairy cows after intramammary administration. J. Integr. Agric. 13:2750-2757.

Lindmark-Månsson, H., C. Bränning, G. Aldén, and M. Paulsson. 2006. Relationship between somatic cell count, individual leukocyte populations and milk components in bovine udder quarter milk. Int. Dairy J. 16:717-727.

Lombard, J.E., G. Zobel, A.E. Adams, C.P. Fossler, C.B. Shivley, N.J. Urie, and C.A. Kopral. 2015. Dry-off procedures on US dairy operations. J. Dairy Sci. 98(E-Suppl. 2):238. (Abstr.).

Mercer, H. D., J. N. Geleta, E. J. Schultz, and W. W. Wright. 1970. Milk-out rates for antibiotics in intramammary infusion products used in the treatment of bovine mastitis: relationship of somatic cell counts, milk production, and drug vehicle. Am. J. Vet. Res. 31:1549-1560.

Neijenhuis, F., H. W. Barkema, H. Hogeveen, and J. P. T. M. Noordhuizen. 2000. Classification and longitudinal examination of callused teat ends in dairy cows. J. Dairy Sci. 83:2795-2804.

NMC. 2006. Recommended Mastitis Control Program. National Mastitis Council, New Prague, MN.

NRC. 2001. Nutrient Requirements of Dairy Cattle. 7th rev. ed. Natl. Acad. Press, Washington, DC.

Mein, G. A., F. Neijenhuis, W. F. Morgan, D. J. Reinemann, J. E. Hillerton, J. R. Baines, I. Ohnstad, M. D. Rasmussen, L. Timms, J. S. Britt, R. Farnsworth, N. Cook, and T. Hemling. 2001. Evaluation of bovine teat condition in commercial dairy herds: 1 . Non-infectious factors. Pages 347-351 in Proceedings of the 2nd International Symposium on Mastitis and Milk Quality 2001, Vancouver, Canada.

Santschi, D. E., and D. M. Lefebvre. 2014. Review: Practical concepts on short dry period management. Can. J. Anim. Sci. 94:381-390.

Schukken, Y. H., J. Vanvliet, D. Vandegeer, and F. J. Grommers. 1993. A randomized blind trial on dry cow antibiotic infusion in a low somatic cell count herd. J. Dairy Sci. 76:2925-2930.

Shoshani, E., S. Rozen, and J. J. Doekes. 2014. Effect of a short dry period on milk yield and content, colostrum quality, fertility, and metabolic status of Holstein cows. J. Dairy Sci. 97:2909-2922.

van Knegsel, A. T. M., G. J. Remmelink, S. Jorjong, V. Fievez, and B. Kemp. 2014. Effect of dry period length and dietary energy source on energy balance, milk yield, and milk composition of dairy cows. J. Dairy Sci. 97:1499-1512.

Whittem, T. 1999. Pharmacokinetics and milk discard times of pirlimycin after intramammary infusion: a population approach. J. Vet. Pharmacol. Ther. 22:41-51.

Zonca, A., M. Gallo, C. Locatelli, S. Carli, P. Moroni, R. Villa, and P. Cagnardi. 2011. Cefquinome sulfate behavior after intramammary administration in healthy and infected cows. J. Dairy Sci. 94:3455-3461. 